\title{
Psychosociale risicosignalering in de zwangerschap, een overzicht van Nederlandse instrumenten
}

\author{
Remy M. Vink, ${ }^{1}$ Symone Detmar ${ }^{1}$
}

\begin{abstract}
Psychosociale risicosignalering tijdens de zwangerschap staat vanuit twee perspectieven in de belangstelling. Enerzijds vanuit de noodzaak om de relatief hoge perinatale sterftecijfers in Nederland terug te dringen; anderzijds omdat veel risicofactoren voor kindermishandeling en -verwaarlozing reeds aanwezig kunnen zijn in de zwangerschap. Inmiddels zijn er in Nederland diverse signaleringsinstrumenten, gericht op het opsporen van deze risicofactoren, in ontwikkeling. In dit artikel worden acht instrumenten beschreven en vergeleken. Er blijkt veel inhoudelijke overeenkomst tussen de instrumenten maar een groot verschil in werkwijze en aantal constructen. Voor een keuze ten behoeve van landelijke implementatie is het echter nog te vroeg omdat nog geen van de signaleringsinstrumenten in voldoende mate gevalideerd is. Duidelijk is wel dat tot samenwerking komen met andere instellingen in verband met aansluitende hulp, evenals training van instrument-gebruikers, essentieel zijn.
\end{abstract}

Trefwoorden: psychosociaal, risicofactor, signaleringsinstrument, perinatale mortaliteit, perinatale morbiditeit, kindermishandeling, depressie

\section{INLEIDING}

Resultaten van de twee Europese PERISTAT-projecten in 2004 en $2008^{1}$ hebben tot een discussie geleid over de wijze waarop de relatief hoge perinatale sterfte in Nederland teruggedrongen kan worden. De stuurgroep 'Zwangerschap en Geboorte' die naar aanleiding van de PERISTAT-resultaten werd ingesteld, adviseerde om aandacht te besteden aan 'systematische risicoselectie' tijdens de zwangerschap om beïnvloedende factoren eerder op het spoor te komen. Daarbij wijst de stuurgroep niet alleen op medische en obstetrische risico's, maar ook op het opsporen en beïnvloeden van psychosociale factoren die een gezonde zwangerschap en bevalling in de weg kunnen staan. ${ }^{2}$ Een toenemend aantal wetenschappelijke studies tonen de (langdurige) invloed aan van psychische en psychosociale gezondheid, omgeving en leefstijl van aanstaande ouders op de zwangerschap en de verdere ontwikkeling van het kind. ${ }^{3-7}$

Sinds een aantal ernstige incidenten staat in Nederland ook de preventie van kindermishandeling en -verwaarlozing sterk in de belangstelling. De 'Inventgroep' adviseerde in 2005 om een 'systematiek van vroegsignalering' in te voeren waarbij ruim vóór de geboorte van het kind

1 TNO Child Health, Leiden risicofactoren voor kindermishandeling en -verwaarlozing in kaart worden gebracht om tijdig te kunnen interveniëren. ${ }^{8}$ Dit betreft factoren zoals psychopathologie, verslaving, onvoldoende sociale steun, partnergeweld, laag opleidingsniveau, kindermishandeling of verwaarlozing in de eigen jeugd..$^{9-12}$ Een adequaat hulpaanbod, aansluitend op signalering van risico's tijdens de zwangerschap, is mogelijk (kosten)effectief in het voorkómen van latere problemen bij opgroeien en opvoeden. ${ }^{8,13}$

Vanuit bovengenoemde perspectieven is de afgelopen jaren aangedrongen op systematische psychosociale risicosignalering in de geboortezorg. De medische en obstetrische risicoselectie is in de verloskunde geregeld via de VIL (Verloskundige IndicatieLijst) ${ }^{14}$ die bepaalt bij welke medische situaties de eerstelijns verloskundige een cliënt doorstuurt naar de gynaecoloog of wanneer overleg nodig is. Psychosociale risicosignalering is echter relatief nieuw onder verloskundigen, kraamverzorgenden en gynaecologen. Nieuw is daarbij ook de samenwerking met nietmedische professionals zoals die in de geestelijke gezondheidszorg, verslavingszorg, maatschappelijk werk etc.

Om verloskundig zorgverleners te ondersteunen bij psychosociale risicosignalering zijn er in de afgelopen jaren diverse instrumenten ontwikkeld. In dit artikel 
wordt een beschrijving gegeven van signaleringsinstrumenten op psychosociaal gebied die momenteel in Nederland rond de zwangerschap worden gebruikt of in ontwikkeling zijn.

\section{SELECTIE VAN}

\section{SIGNALERINGS -}

\section{INSTRUMENTEN}

Alle ontwikkelaars van signaleringsinstrumenten, voor zover bij ons bekend, zijn benaderd voor informatie. Daarnaast is gebruik gemaakt van informatie via Internet (uit Nederland afkomstige pagina's). Signaleringsinstrumenten zijn vervolgens op basis van de volgende criteria geïncludeerd.

1 Het instrument is bedoeld voor toepassing in de professionele praktijk van de Nederlandse zorg rond zwangerschap, bevalling en kraamtijd.

2 Het instrument richt zich (onder andere) op psychosociale factoren die bewezen geassocieerd zijn met perinatale morbiditeit en -mortaliteit, depressie, problematisch opgroeien en opvoeden en kindermishandeling en -verwaarlozing.

3 Het betreft een universeel in te zetten signaleringsinstrument ten behoeve van risicoselectie, verwijzing en/ of extra begeleiding (geen diagnostisch instrument of instrument voor uitsluitend wetenschappelijke doeleinden).(noot a)

$4 \mathrm{Er}$ is sprake van (proef)implementatie in Nederland.

5 Instrumenten zijn of worden wetenschappelijk gefundeerd.

$6 \mathrm{Er}$ is voldoende informatie beschikbaar over het instrument.

De volgende acht signaleringsinstrumenten voldoen aan deze criteria: de ALPHA-NL, Checklist Vroegsignalering, (D)FSI, DMO-9, EPDS, GyPsy, R4U en Voorzorg-criteria. Een prenatale versie van de SPARK (Structured Problem Analysis of Raising Kids - voorheen VOBO-Z ${ }^{15}$ is niet geïncludeerd omdat deze nog te zeer in de fase van ideevorming verkeert. Daarnaast zijn enkele vragenlijsten van ziekenhuizen en kraamzorgorganisaties niet geïncludeerd omdat er onvoldoende informatie van beschikbaar was of te weinig wetenschappelijke basis aangegeven kon worden.

De geselecteerde instrumenten worden hierna beschreven (in alfabetische volgorde) en zijn samengevat in tabel 1.

\section{BESCHRIJVING SIGNALERINGSINSTRUMENTEN}

\section{ALPHA-NL}

De ALPHA-NL is een Nederlandse vertaling van de Canadese ALPHA (Antenatal Psychosocial Health Assessment). ${ }^{16-18}$ De ALPHA-NL is ontwikkeld door TNO via focusgroepen met verloskundigen, gynaecologen en jeugdverpleegkundigen en op basis van de ervaringen binnen het project 'Implementatie Screenen op huiselijk geweld in de verloskundigenpraktijk' (20042008).

Doel: prenataal signaleren van risicofactoren voor kindermishandeling en -verwaarlozing, problematisch opgroeien en opvoeden, partnergeweld en relatieproblemen, depressie.

Indicatie voor psychosociale hulp tijdens de zwangerschap.

Gebruikers: verloskundig zorgverleners (in tweede en derde lijn eventueel verpleegkundigen).

Beschrijving: de ALPHA-NL is een self-report vragenlijst met 48 vragen die vijftien gevalideerde risicofactoren betreffen ${ }^{11}$ met overwegend 5-punts Likertschaal antwoordopties. De vragen vormen een aanvulling op de algemene, medische en obstetrische gegevens die al uit de intake bekend zijn. De WAST (Women Abuse Screening Tool) ${ }^{19}$ en de CAGE-questionnaire (over alcohol en drugsgebruik) ${ }^{20}$ maken deel uit van de ALPHA(-NL).

Werkwijze: de ALPHA-NL wordt alle cliënten (universeel) aangeboden, zo vroeg mogelijk in de zwangerschap. Het invullen gebeurt in de wachtruimte voorafgaand aan een consult. De verloskundige bespreekt de resultaten met de zwangere/aanstaande ouders, brengt met cliënte(n) in kaart wat de hulpbehoefte is en wat nodig is voor een goede start met de baby. Training van de verloskundig zorgverleners is noodzakelijk evenals het vastleggen van samenwerkingsafspraken met instellingen en programma's, over het vervolg op signalen. De ALPHA-NL maakt deel uit van een samenhangend programma van activiteiten gericht op de perinatale preventie van kindermishandeling en -verwaarlozing (Vroeg Erbij).

Toepassing en onderzoek: proefimplementaties zijn uitgevoerd in Amsterdam Noord en Zaanstad in 2009 $(\mathrm{n}=355)$ resulterend in 13\% twijfelachtige tot zorgwekkende gezinssituaties en $9 \%$ (van 355) verwijzingen naar vormen van begeleiding tijdens de zwangerschap. De acceptatie van de ALPHA-NL is zowel onder verloskundig zorgverleners als cliënten goed. ${ }^{21}$ In 2011 is in het kader van de richtlijn 'Vroegsignalering en gegevensoverdracht pasgeborenen Amsterdam' de ALPHA-NL in de gehele stad geïmplementeerd en is een nulmeting uitgevoerd; de evaluatie is nog niet afgerond. Proefimplementaties zijn tevens uitgevoerd in de regio Helmond, Winterswijk, Leeuwarden, Breda en Assen.

\section{Checklist Vroegsignalering}

De 'Checklist Vroegsignalering in de kraamtijd' is een doorontwikkeling van het signaleringsinstrument dat 


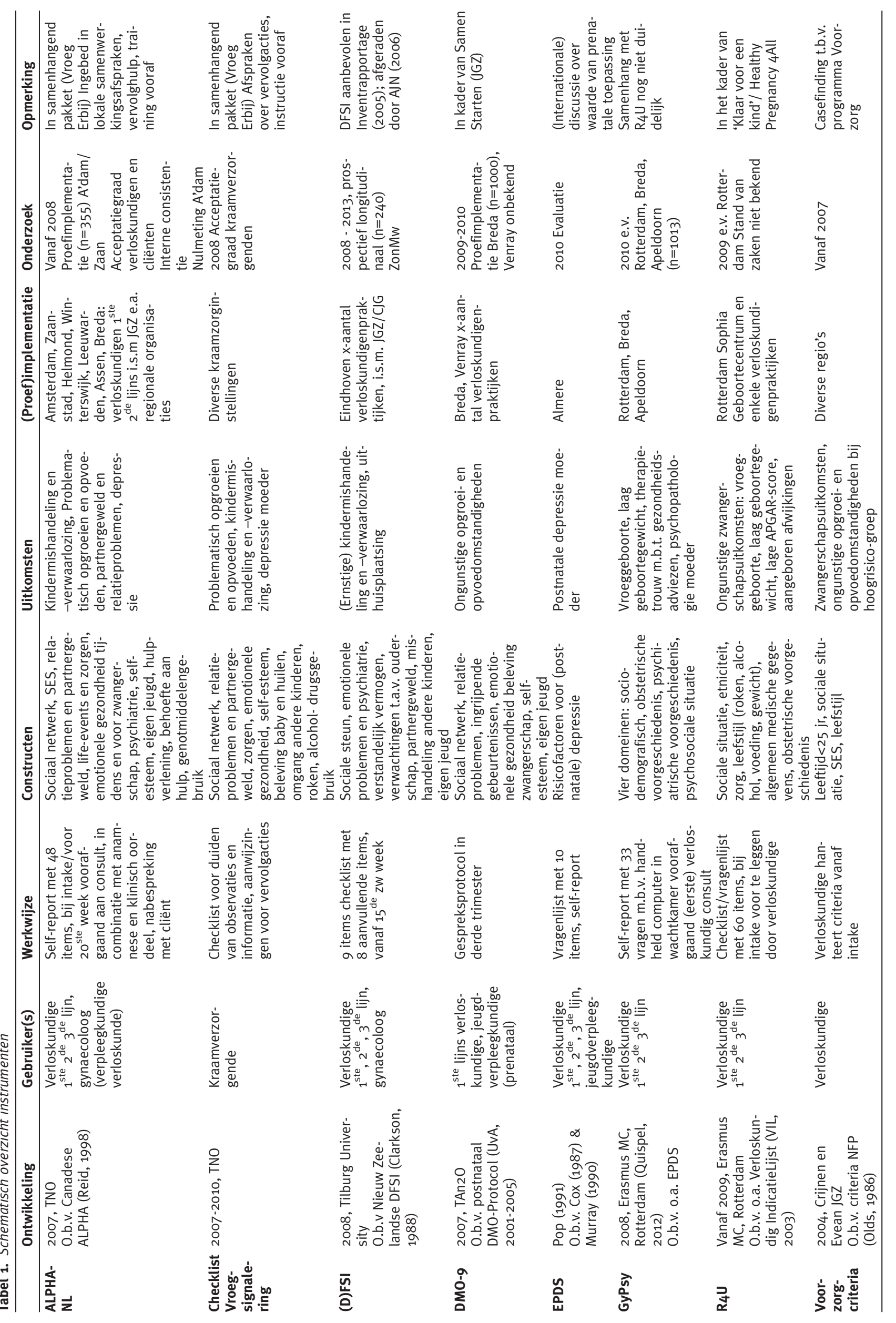


door TNO in 2006 in opdracht van het ministerie van VWS is ontwikkeld. ${ }^{22}$

Doel: kraamverzorgenden kunnen signalen van mogelijke psychosociale problemen, duiden.

Gebruikers: kraamverzorgenden.

Beschrijving: de 'Checklist Vroegsignalering in de kraamtijd' bestaat uit 35 items die betrekking hebben op psychosociale zorgbehoefte en op risicofactoren voor of signalen van kindermishandeling en -verwaarlozing en depressie bij de kraamvrouw. Het betreft dezelfde gevalideerde risicofactoren als die van de ALPHA-NL.

Werkwijze: de checklist wordt niet door de kraamverzorgende bij de ouders uitgevraagd maar geeft handvatten om observaties in het gezin te duiden. Dit resulteert in handelingsopties: overleg met de verloskundige onder wiens verantwoordelijkheid zij werkt, met de teamleider of de jeugdgezondheidszorg en indien mogelijk met de ouders. Training van kraamverzorgenden wordt aanbevolen.

Toepassing en onderzoek: het instrument is, na training van kraamverzorgenden, toegepast in ruim 400 kraamgezinnen waarvan bij bijna 9\% signalen naar de jeugdgezondheidszorg zijn gerapporteerd. De checklist wordt breed gebruikt in de kraamzorg.

\section{(D)FSI}

De DFSI (Dunedin Family Services Indicator) ${ }^{23}$ is in Nieuw-Zeeland ontwikkeld en vertaald naar de Nederlandse situatie waarbij acht items aan de oorspronkelijke negen zijn toegevoegd. De DFSI werd door de 'Inventgroep ${ }^{8}$ genoemd als een van de instrumenten die mogelijk in de Nederlandse geboortezorg geïmplementeerd zouden kunnen worden ter preventie van ongunstige opgroei- en opvoedomstandigheden voor kinderen.

Doel: opsporen van aanstaande ouders met een (hoog) risico op toekomstige kindermishandeling en -verwaarlozing.

Gebruikers: verloskundig zorgverleners.

Beschrijving: de Nederlandse (D)FSI is een checklist met zeventien items als leidraad in gesprek met cliënte(n).

Werkwijze: de (D)FSI wordt vanaf de vijftiende zwangerschapsweek toegepast in gesprek met de zwangere/ aanstaande ouders. Verwijzing vindt onder andere plaats naar het programma 'Baby Extra' voor zwangeren met psychische problemen of een psychiatrische achtergrond.

Toepassing en onderzoek: in 2008 is het project 'In verwachting' geïnitieerd (Tilburg University/ZonMw) waarbij in een prospectieve longitudinale studie de effectiviteit van de aangepaste versie van de DFSI wordt onderzocht. Het project wordt uitgevoerd in Eindhoven in eerstelijns verloskundigenpraktijken in samenwerking met 'Baby Extra' en het Centrum voor Jeugd en Gezin (CJG/JGZ). Resultaten van het onderzoek worden verwacht in 2013. De (D)FSI wordt verder niet in Nederland gebruikt. In Nieuw Zeeland is de voorspellende waarde van de DFSI bepaald in de obstetrische praktijk in Dunedin (inwoneraantal: 100.000). Ten aanzien van de uitkomstmaten 'verwijzing naar 'social work' en 'child protection services' binnen twee jaar postpartum', is de
Nieuw Zeelandse DFSI sensitief $(100 \%, \mathrm{p}<0,001)$ en specifiek ( $87 \%$ resp. $81 \%, \mathrm{p}<0,001)$ gebleken. ${ }^{23}$

\section{DM0-9}

De DMO-9 is ontwikkeld door Tan2O (2009) en is een afgeleide van het DMO-Protocol dat vanaf acht weken postpartum in de jeugdgezondheidszorg 0-4 wordt gebruikt in het kader van het programma Samen Starten (Tan/UvA/Gemeente Amsterdam, 2005).

Doel: in kaart brengen en monitoren van de psychosociale gezinssituatie voor de geboorte, signaleren van zorgwekkende omstandigheden voor kinderen.

Gebruikers: eerstelijns verloskundige of jeugdverpleegkundige prenataal.

Beschrijving: het DMO-9 is een self-report vragenlijst en bestaat uit 43 items die betrekking hebben op: beleving van de zwangerschap, rol van de partner, sociale steun, omstandigheden, eigen jeugd, ingrijpende gebeurtenissen. Antwoordopties bestaan voornamelijk uit 5-punts schalen.

Werkwijze: de resultaten worden in een uitgebreid consult met de aanstaande ouders nabesproken. Training van de verloskundigen/verpleegkundigen is noodzakelijk.

Toepassing en onderzoek: het DMO-9 is geimplementeerd in eerstelijns verloskundigenpraktijken in Breda en Venray. Van de ruim 1000 toegepaste protocollen DMO-9 in Breda, leidde dit in $2 \%$ van de gevallen tot verwijzing naar vormen van psychosociale hulp. ${ }^{24}$ Wat het vervolg is in beide regio's is op het moment van schrijven onbekend.

\section{EPDS}

De EPDS, Edinburgh Postnatal Depression Scale ${ }^{25}$ is vertaald naar het Nederlands. ${ }^{26}$ De EPDS is ontwikkeld voor postnataal gebruik maar wordt (internationaal) ook wel prenataal toegepast.

Doel: signalering en preventie van (postnatale) depressie.

Gebruikers: verloskundig zorgverleners / zorgverleners postpartum.

Beschrijving: de EPDS is een zelf-scorelijst met tien vragen over gevoelens van angst en depressie in de voorafgaande week. De lijst is genormeerd en hanteert een afkappunt.

Werkwijze: de EPDS kan op ieder moment door de zwangere of kraamvrouw ingevuld worden en nabesproken met de verloskundig zorgverlener.

Toepassing en onderzoek: de Nederlandse EPDS is gevalideerd en betrouwbaar $(\alpha=0,82)$ voor postnataal gebruik. ${ }^{26}$ De EPDS wordt in Nederland prenataal toegepast in de eerste- en tweedelijns verloskunde in Almere en Rotterdam (via de GyPsy, zie hierna). De EPDS wordt ook in andere regio's gebruikt maar dan als referentie- of meetinstrument in wetenschappelijk onderzoek.

\section{GyPsy}

De GyPsy Screen \& Advies Tool is ontwikkeld door het Erasmus MC, Rotterdam in 2008.

Doel: het opsporen van psychopathologie, psychoso- 
ciale problemen en middelengebruik tijdens de zwangerschap.

Gebruikers: verloskundig zorgverleners.

Beschrijving: de GyPsy bevat 33 items, waaronder vragen van de EPDS, ${ }^{26}$ aanvullende vragen op psychosociaal gebied en vragen over middelengebruik.

Werkwijze: de GyPsy wordt ingevuld door de zwangere, voorafgaand aan een (eerste) consult, op een handheld computer en geeft via algoritmen direct uitslag of zij in aanmerking komt voor psychische begeleiding tijdens de zwangerschap. Zij laat de uitslag zien aan de verloskundig zorgverlener die haar vervolgens adviseert of verwijst. Een online-versie is in ontwikkeling (Mind2Care).

Toepassing en onderzoek: de GyPsy is in 2010 onderzocht in drie, zowel eerste- als tweedelijns, verloskundigenpraktijken in Rotterdam $(\mathrm{n}=621)$. De interne betrouwbaarheid varieerde van 0,88 tot 0,90 ; test-hertest betrouwbaarheid varieerde van 0,64 tot 1,00. De positieve predictieve waarde van de GyPsy was $86 \%$ en de negatief voorspellende waarde $97 \% .{ }^{27}$ Vervolgonderzoek is tevens uitgezet in Breda, Apeldoorn, Meppel, Zwolle waarbij ook zwangerschapsuitkomsten (onder andere vroeggeboorte en laag geboortegewicht) worden vergeleken met de uitkomsten op de GyPsy.

\section{R4U}

De R4U (Rotterdam Reproductive Risk Reduction checklist) is vanaf 2009 in ontwikkeling bij het Erasmus MC in het kader van het tienjarige Rotterdamse programma 'Klaar voor een kind' en het landelijke 'Healthy Pregnancy 4All'.

Doel: risicofactoren voor congenitale afwijkingen, laag geboortegewicht en vroeggeboorte opsporen om perinatale mortaliteit en morbiditeit terug te dringen. ${ }^{28}$ Bieden van een gemeenschappelijke taal bij bespreking binnen een VSV (eerste- en tweedelijns verloskundig samenwerkingsverband).

Gebruikers: verloskundig zorgverleners.

Beschrijving: de R4U is een lijnoverstijgende checklist voor geprotocolleerde risicoselectie. De lijst bestaat uit 60 items betreffende: sociale-economische situatie, etniciteit, zorgsituatie, leefstijl (roken, alcohol, drugs, geneesmiddelen, BMI), medische gegevens en obstetrische voorgeschiedenis. Voor deze laatste twee domeinen wordt de VIL gebruikt. De uitkomsten resulteren in de score van 'geen risico', een 'gespecificeerd risico' of een 'totaalrisico' (risicocumulatie).

Werkwijze: de R4U wordt gebruikt tijdens het eerste verloskundig consult en later in de zwangerschap. Met lokale ketenpartners worden aansluitende 'zorgpaden' afgesproken.

Toepassing en onderzoek: de R4U is in ontwikkeling en wordt momenteel getest en onderzocht in een eerstelijns verloskundigenpraktijk en in het Sophia Geboortecentrum te Rotterdam. Blauwdrukken van de zorgpaden worden momenteel in proefprojecten getest. Het instrument is nog niet gevalideerd; proefimplementaties en onderzoek zijn in uitvoering. Een trial is aangemeld bij het Nederlandse Trial Register.

\section{Voorzorg-criteria}

Het programma Voorzorg is een vertaling van het Amerikaanse programma Nurse-Family Partnership, ${ }^{29}$ in 2004 door A. Crijnen in Nederland geïntroduceerd.

Doel: casefinding op basis van criteria, ten behoeve van instroom in het programma Voorzorg. Dit programma beoogt: verbetering van het zwangerschaps- en geboorteproces, verbetering gezondheid en ontwikkeling van het kind, verbetering persoonlijke ontwikkeling van moeder (onder andere opleiding en werk).

Gebruikers: verloskundig zorgverleners.

Beschrijving: de Voorzorg-criteria zijn: de zwangere is maximaal 25 jaar; laagopgeleid; maximaal 28 weken zwanger; beheerst (enigszins) de Nederlandse taal en heeft niet eerder een levend geboren kind gehad. Met Voorzorg worden hoog-risico zwangeren vanaf de zestiende zwangerschapsweek tot twee jaar postpartum door huisbezoeken van een gespecialiseerde jeugdverpleegkundige intensief begeleid naar adequaat moederschap en terugdringen van risicofactoren met betrekking tot kindermishandeling en -verwaarlozing.

Werkwijze: in de regio's waar Voorzorg loopt, wordt bij iedere verloskundige intake nagegaan of de zwangere voldoet aan de criteria voor deelname aan het programma.

Toepassing en onderzoek: Voorzorg wordt toegepast in ongeveer vifftien regio's. Onderzoek naar de effecten van het programma Voorzorg loopt sinds 2007.

\section{SIGNALERINGSINSTRUMENTEN VERGELEKEN}

Van de acht geïncludeerde instrumenten zijn er zeven ontwikkeld voor gebruik door de verloskundig zorgverlener in de vroege prenatale periode vanaf de intake; één instrument is ontwikkeld voor in de kraamtijd met de kraamverzorgende als gebruiker (Checklist Vroegsignalering).

De meeste signaleringsinstrumenten zijn vanuit het kader van de jeugdsector en jeugdgezondheidszorg ontwikkeld; de R4U is ontwikkeld vanuit de medische sector en de EPDS en GyPsy komen voort uit respectievelijk de geestelijke gezondheidszorg (GGZ) en POP-poli (psychiatrie, obstetrie, pediatrie). Dientengevolge zijn er verschillen in doelstellingen: de ALPHA-NL, DMO-9 mnd, Checklist Vroegsignalering, (D)FSI en Voorzorg-criteria richten zich op de preventie van problematisch opgroeien en opvoeden en kindermishandeling en -verwaarlozing. Daarbij ligt de focus van de (D)FSI en Voorzorg-criteria met name op het signaleren van hoog-risico omstandigheden voor kinderen. De R4U heeft als doel de perinatale morbiditeit en mortaliteit terug te dringen en de EPDS en GyPsy zijn vooral gericht op depressiepreventie.

De instrumenten hanteren verschillende werkwijzen. Vier instrumenten (ALPHA-NL, EPDS, DMO-9, GyPsy) bestaan uit een vragenlijst die door de zwangere zelf wordt ingevuld en vervolgens besproken met de zorgverlener. Daarvan maakt één instrument gebruik van een handheld computer (GyPsY). De andere instrumenten hebben de vorm van een checklist (of lijst criteria zoals bij Voorzorg) waarbij er drie gebruikt worden in een inventariserend gesprek met de cliënt en alleen de Checklist 
Vroegsignalering de observaties van de kraamverzorgende duidt. Alleen de GyPsy en EPDS zijn genormeerd.

Met uitzondering van de EPDS hanteren alle instrumenten vergelijkbare maar niet evenveel constructen (sociale steun, genotmiddelengebruik, partnergeweld, life-events en dergelijke). De R4U hanteert naast psychosociale ook medische en obstetrische risico's (medicatie, chronische ziekte, voeding, BMI en dergelijke). De EPDS vraagt alleen naar psychisch welbevinden in de voorafgaande week. Geen van de zelf-invullijsten heeft een versie voor de partner/aanstaande vader; partnerfactoren worden in beperkte mate alleen via de zwangere uitgevraagd of door haar ingevuld. De vier zelf-invul vragenlijsten zijn vooralsnog alleen Nederlandstalig, niet cultuursensitief en (nog) niet geschikt voor laaggeletterden.

Alle instrumenten vragen om aansluitende actie(s) van de verloskundig zorgverlener of verwijzing naar een of meerdere vormen van hulp. Bijvoorbeeld de Criteria Voorzorg selecteert een nauw omschreven hoog-risicogroep voor het gelijknamige programma en de Checklist Vroegsignalering resulteert in handelingsopties voor de kraamverzorgenden. De ALPHA-NL, R4U, GyPsy en DMO-9 resulteren in een breder scala aan acties (bij de R4U 'zorgpaden' genoemd) al naar gelang de lokale sociale kaart. Alleen de R4U en ALPHA-NL en Checklist Vroegsignalering zijn ingebed in bredere programma's (respectievelijk 'Klaar voor een kind' en 'Vroeg Erbij'). Training is ontwikkeld rond de ALPHA-NL, Checklist Vroegsignalering, DMO-9 en (D)FSI. Ten aanzien van de R4U, EPDS, GyPsy en Voorzorg-criteria is dit niet het geval of niet bekend.

Alle instrumenten behalve de Checklist Vroegsignalering, zijn nog in ontwikkeling en/of in onderzoek en worden slechts op kleine schaal in proefimplementaties gebruikt. De Checklist Vroegsignalering wordt binnen een groot aantal (grote) kraamzorginstellingen gehanteerd.

De ALPHA-NL, GyPsy, R4U en Checklist Vroegsignalering zijn (of worden) onderzocht op acceptatie door de professional en het gebruik in de praktijk. Ten aanzien van de andere instrumenten is dit niet het geval of niet bekend. Clientervaringen zijn onderzocht ten aanzien van de GyPsy en de ALPHA-NL.

Geen van de instrumenten is op dit moment in voldoende mate gevalideerd. RCT's (Randomized Controlled Trials) zijn nog niet in Nederland uitgevoerd of in uitvoering. De DFSI, ALPHA en Voorzorg zijn wel (op onderdelen) gevalideerd via RCT's in de landen van herkomst. ${ }^{23,16,17,29}$ Voor de R4U is een trial aangemeld bij het Nederlandse Trial Register. De EPDS is in Nederland wel gevalideerd ten aanzien van sensitiviteit en specificiteit voor postnataal gebruik ${ }^{26}$ maar niet voor prenataal gebruik. Sommige instrumenten hebben andere gevalideerde instrumenten geïncorporeerd (de WAST en CAGE in de ALPHA-NL; de EPDS in de GyPsy). Daarnaast baseren de ALPHA-NL, R4U en GyPsy zich op systematische reviews. Ook wordt face validity gevonden in de validiteit van de postnatale instrumenten waarvan een prenatale variant ontwikkeld is (DMO-9 en EPDS).

\section{DISCUSSIE}

Psychosociale risicosignalering tijdens de zwangerschap, gericht op het terugdringen van ongunstige uitkomsten voor moeder en kind, staat momenteel zeer in de belangstelling. Een inventarisatie op basis van criteria, leverde acht signaleringsinstrumenten op die voor de Nederlandse geboortezorg zijn ontwikkeld. Zijn deze instrumenten alle noodzakelijk?

Geen van de signaleringsinstrumenten is op dit moment in voldoende mate gevalideerd. Het is daarom te vroeg om op basis van bewezen effectiviteit en acceptatie er nu één als optimaal te beoordelen voor landelijke uitrol. Meer onderzoek is daarvoor nodig.

Het merendeel van de signaleringsinstrumenten is inhoudelijk vergelijkbaar maar de instrumenten betreffen verschillende ongunstige uitkomsten (perinatale mortaliteit en morbiditeit; kindermishandeling en -verwaarlozing; depressie). De instrumenten verschillen vooral in aantal constructen en in werkwijze. Er is sprake van gemeenschappelijke risicofactoren die, in eerste instantie, de zwangerschapsuitkomsten beïnvloeden maar ook langduriger invloed op moeder en kind kunnen hebben. Bijvoorbeeld: partnergeweld tijdens de zwangerschap kan leiden tot vroeggeboorte ${ }^{30}$ en tot depressie bij de moe$\mathrm{der}^{31}$ maar is tevens een risicofactor voor kindermishandeling en -verwaarlozing later in de tijd. ${ }^{32}$ Dit betekent mogelijk dat volstaan kan worden met instrumenten die risicofactoren voor kindermishandeling en -verwaarlozing signaleren, in de veronderstelling dat daarmee ook de psychosociale risicofactoren voor perinatale mortaliteit en morbiditeit gedekt zijn. In aanmerking komen: de ALPHA-NL, (D)FSI, GyPsy, DMO-9 ten behoeve van de verloskunde en de Checklist Vroegsignalering voor de kraamzorg. Daarnaast is een uitbreiding van de VIL met psychosociale risicofactoren voor perinatale sterfte, mogelijk.

Bij ongunstige psychosociale situaties zijn er vervolgens twee scenario's voor de follow-up: de verloskundig zorgverlener verwijst naar en overlegt met professionals in het psychosociale domein. Voorwaarde is dat de verloskundig zorgverlener goed ingevoerd is in de lokale sociale kaart en nauwe banden heeft met relevante instellingen. Dit kost echter tijd en is niet de kernexpertise van de medisch georiënteerde verloskundig zorgverlener. In een tweede scenario neemt de jeugdverpleegkundige wiens expertise dit wél is op grond van de Wet Publieke Gezondheid (WPG), deze rol van de verloskundig zorgverlener over. In sommige (ALPHA-NL-) regio's kan de reguliere jeugdverpleegkundige, op indicatie van de verloskundig zorgverlener, al vroeg in de zwangerschap komen om aanstaande ouders, op psychosociaal vlak, te begeleiden naar een goede start met de baby.

Deze werkwijze sluit aan bij de attitudeverschuiving die waargenomen kan worden in de jeugdgezondheidszorg en het psychosociale domein. Daar voltrekt zich de laatst jaren een verschuiving van een risico- en probleemgerichte benadering naar een houding van oplossingsgericht werken, ${ }^{33}$ mét cliënten, vanuit eigen kracht en zelfmanagement. Een goede relatie opbouwen met de cliënt is des te belangrijker omdat ouders schijnbaar 
steeds minder de vele vragenlijsten accepteren die hen bij het consultatiebureau worden voorgelegd. ${ }^{34}$ Ook de bescherming van de persoonsgegevens speelt daarbij een rol.

De focus op kindermishandeling en -verwaarlozing kan de indruk wekken dat signaleringsinstrumenten met name de ernstige en complexe (multiproblem) cases moeten kunnen opsporen. Vanzelfsprekend moeten instrumenten daarvoor voldoende sensitief zijn. Echter, vanuit het oogpunt van preventie is het belangrijk om ook andere situaties met risico op problematische opgroeien en -opvoeden te kunnen signaleren.

Het professionele oordeel zal daarnaast altijd belangrijk blijven voor de interpretatie van bevindingen. Zeker zo belangrijk zijn waargenomen neveneffecten van de ALPHA-NL: de bewustwording bij aanstaande ouders, het aangaan van de dialoog, het bespreekbaar maken van taboe-onderwerpen en normaliseren dat cliënten met psychosociale vragen (ook later in de zwangerschap) bij de verloskundig zorgverlener terecht kunnen. ${ }^{21}$

Dit bespreekbaar maken is echter niet gemakkelijk, vooral wanneer dit met het oog op het latere opgroeien en opvoeden plaatsvindt. In de communicatie met cliënten kan dan juist wel het gemeenschappelijke korte termijn doel, namelijk een gezonde zwangerschapsuitkomst, een goede ingang zijn.

De voorgaande punten resulteren in twee essentiële voorwaarden bij de keuze en implementatie van een signaleringsinstrument. Ten eerste dient de implementatie gepaard te gaan met training van de verloskundig zorgverleners die het instrument gaan toepassen. Daarin moet er ruim aandacht zijn voor 'handelingsverlegenheid': voor het kunnen bespreken van gevoelige thema's met aanstaande ouders en het overwinnen van schroom om hen (ook bij lichtere problematiek) te verwijzen naar hulp. Ten tweede zullen de verloskundig zorgverleners en de jeugdgezondheidzorg en/of zorgverleners in het psychosociale domein elkaar moeten vinden en samenwerkingsafspraken moeten maken.

\section{CONCLUSIE}

Dit artikel geeft een overzicht van de Nederlandse signaleringsinstrumenten die gericht zijn op het opsporen van psychosociale factoren tijdens de zwangerschap die van invloed kunnen zijn op perinatale morbiditeit en mortaliteit, problematische opgroeien en opvoeden, kindermishandeling en -verwaarlozing en depressie. Op grond van criteria zijn acht instrumenten geïncludeerd: de ALPHA-NL, Checklist Vroegsignalering, (D)FSI, DMO9, EPDS, GyPsy, R4U en Voorzorg-criteria.

De instrumenten vertonen inhoudelijk veel overeenkomst en variëren vooral in aantal constructen en werkwijze. Vanwege gemeenschappelijkheid van risicofactoren kan mogelijk volstaan worden met signaleringsinstrumenten die gericht zijn op de preventie van kindermishandeling en -verwaarlozing en kunnen psychosociale risicofactoren die van invloed zijn op perinatale mortaliteit en morbiditeit opgenomen worden in de VIL.

Het is nog te vroeg om te bepalen welke signaleringsinstrumenten het beste passen in de hedendaagse Neder- landse geboortezorg. Daarvoor is meer onderzoek nodig ten aanzien van de bruikbaarheid en validiteit van de instrumenten.

Bij ieder signaleringsinstrument geldt dat training van de verloskundig zorgverleners belangrijk is om onder andere 'handelingsverlegenheid' te overwinnen. Daarnaast is een goede samenwerking zowel tussen de lijnen als met de jeugdgezondheidszorg en/of andere instellingen die cliënten op psychosociaal vlak kunnen begeleiden, van groot belang.

\section{DANKWOORD}

Prof. dr. H.J.A. van Bakel (Tilburg University); Prof. dr. G.J. Bonsel, C. Quispel MSc, dr. S. Denktaş (Erasmus MC), drs. I. Staal (GGD Zeeland).

\section{NoOT}

a In de geboortezorg wordt gesproken van 'risicosignalering en risicoselectie'. ${ }^{14}$ In de jeugd(gezondheids)zorg en het psychosociale domein spreekt men van 'vroegsignalering' ${ }^{8}$ waarbij het proces van selecteren voor een ondersteunings- of hulpaanbod, impliciet wordt verondersteld.

\section{ABSTRACT}

Psychosocial risk assessment during pregnancy, an overview of Dutch tools

Psychosocial health assessment during pregnancy is a novel issue in Dutch midwifery and obstetric care. Perinatal morbidity and mortality are relatively high in the Netherlands compared to other European countries and the need for prevention is stressed in the field. The issue is also relevant from the perspective of prevention of child abuse and neglect and other adverse childhood experiences which can already be recognized during pregnancy. A number of perinatal psychosocial health assessment tools have been developed in the past years. In this article we discuss eight Dutch tools. These assessment tools vary in procedure and in the number of concepts assessed. Outcomes however are very similar. None of the tools is validated yet and we therefore cannot recommend specific tools for implementation on the basis of evidence. Two conditions however are crucial: training of midwives and obstetricians and collaboration with referral agencies.

Keywords: risk assessment, psychosocial, perinatal morbidity, depression, child abuse, child neglect

\section{LITERATUUR}

1. Achterberg $P W$, Kramers PGN. Een gezonde start? Sterfte rond de geboorte in Nederland: trends en oorzaken vanuit een internationaal perspectief. Rapport 271558003. Bilthoven: RIVM, 2001.

2. Stuurgroep Zwangerschap en Geboorte. Een goed begin, veilige zorg rond zwangerschap en geboorte. Advies Stuurgroep Zwangerschap en Geboorte. Utrecht Stuurgroep Zwangerschap en Geboorte, 2009

3. Doesem KTM van, Hosman CMH, Riksen-Walraven JM. A model-based intervention for depressed mothers and their infants. Infant Mental Health J 2005;26:157-67. 
4. Loomans EM, Dijk AE van, Vrijkotte TG et al. Psychosocial stress during pregnancy is related to adverse birth outcomes: results from a large multi-ethnic community-based birth cohort. Eur J Public Health 2012 Jul 31. [Epub ahead of print]

5. Loomans EM, Stelt $O$ van der, Eijsden $M$ van, et al Antenatal maternal anxiety is associated with problematic behaviour at age five. Early Human Devel 2011;87:565-70.

6. Weitzman M, Gortmaker S, Sobol A. Maternal smoking and behavior problems of children. Pediatrics 1992;90:342-9.

7. Linnet KM, Dalsgaard S, Obel C, Wisborg K, et al Maternal lifestyle factors in pregnancy risk of attention deficit hyperactivity disorder and associated behaviors: Review of the current evidence. Am J Psychiatry 2003;160:1028-40.

8. Hermanns J, Öry F, Schrijvers G (Inventgroep) Helpen bij opgroeien en opvoeden: eerder, sneller en beter. Een advies over vroegtijdige signalering en interventies bij opvoed- en opgroeiproblemen. Den Haag, Ministerie van WVS, 2005.

9. Sidebotham P, Heron J, ALSPAC Study Team. Child maltreatment in the 'children of the nineties': a cohort study of risk factors. Child Abuse Negl 2006;30:497-522.

10. Tremblay RE, Japel C. Prevention during pregnancy, infancy and the preschool years. In DP Farrington, JW Coid (eds.) Early Prevention of Adult Antisocial Behaviour. Cambridge: Cambridge University Press, 2003, p. 205-264.

11. Wilson LM, Reid AJ, Midmer DK, Biringer A, Carroll JC, Stewart DE. Antenatal Psychosocial Risk Factors Associated with Advers Postpartum Family Outcomes. Systematic Review. CMAJ 1996;154:785-99.

12. Alink L, IJzendoorn $R$ van, Bakermans-Kranenburg $M$ et al. Kindermishandeling in Nederland Anno 2010 : de Tweede Nationale Prevalentiestudie Mishandeling van kinderen en jeugdigen (NPM 2010). Leiden: Casimir, 2011.

13. Carneiro P, Heckman JJ. Human Capital policy. Working Paper 9495. Cambridge MA: National Bureau of Economic Research, 2003.

14. College voor Zorgverzekeringen. Verloskundig vademecum 2003. Eindrapport van de Commissie Verloskunde. Diemen: CVZ, 2003.

15. Stel H van, Staal IIE, Hermanns JMA, Schrijvers AJP. Validity and reliability of a structured interview for early detection and risk assessment of parenting and developmental problems in young children: a cross-sectional study. BMC Pediatrics 2012; 12:71 doi:10.1186/1471-2431-12-71.

16. Carroll JC, Reid AJ, Biringer A, et al Effectiveness of the Antenatal Psychosocial Health Assessment (ALPHA) form in detecting psychosocial concerns: a randomized controlled trial. CMAJ 2005;173:253-9.

17. Blackmore ER, Carroll JC, Reid AJ et al The use of the antenatal psychosocial health assessment (ALPHA) tool in the detection of psychosocial risk factors for postpartum depression: a randomized controlled trial. J Obstet Gynecol Can 2006;28: 873-4.
18. Midmer DK, Bryanton J, Brown R. Assessing antenatal psychosocial health. Randomized controlled trial of two versions of the ALPHA form. Can Fam Physician 2004;50:80-7.

19. Weiss SJ, Ernst AA, Cham E, Nick TG. Development of a screen for ongoing intimate partner violence. Violence Vict 2003;18: 131-41.

20. Ewing JA Detecting Alcoholism: The CAGE Questionnaire. JAMA 1984;252:1905-7 PMID 6471323.

21. Vink, RM, Rijnders MEB, Dommelen P van, Broerse A. Vroeg signaleren van ongunstige opgroeiomstandigheden door verloskundigen in Zaanstad en Amsterdam-Noord. Leiden: TNO Kwaliteit van Leven, 2009.

22. Jonge A de, Korfker DG, Vogels AGC, Pal SM van der, Vink RM, et al Preventie en vroegsignalering van risicogezinnen in de kraamzorg, Leiden: TNO Kwaliteit van Leven, 2007.

23. Muir R, Monogan S, Gilmore R, Clarkson J, et al. Predicting child abuse and neglect in New Zealand. Austr NZ J Psychiatry 1989;23:255-60.

24. Konings F. Evaluatie protocol DMO-9 maanden. Breda: GGD West-Brabant, 2011.

25. Cox JL, Holden JM, Sagovsky R. Detection of postnatal depression: Development of the 10-item Edinburgh Postnatal Depression Scale. Br J Psychiatry 1987;150:782-6.

26. Pop VJM, Komproe IH, van Son MJ. Characteristics of the Edinburgh Post Natal Depression Scale in the Netherlands. J Affect Disorders 1992;26:101-10.

27. Quispel C, Bonsel GJ, Schneider AJ, Lambregtse-van den Berg $M P$. An innovative screen-and-treat tool for psychopathology and psychosocial problems of urban pregnant women. J Psychosom Obstet Gynecol 2012;33:7:14.

28. Bonsel GJ, Birnie E, Denktas S, Steegers EAP. Signalementstudie zwangerschap en geboorte, lijnen in de perinatale sterfte. Rotterdam: Erasmus MC, 2009.

29. Olds DL, Henderson CR. Improving the Delivery of Prenatal Care and Outcomes of Pregnancy: A Randomized Trial of Nurse Home Visitation. Pediatrics 1986;77:16-28.

30. Rodrigues T, Rocha L, Barros H. Physical abuse during pregnancy and preterm delivery. Am J Obstet Gynecol 2008;198: 171. e1-6 197.

31. Golding JM. Intimate partner violence as a risk factor for mental disorders: a meta-analysis. J Fam Violence 1999;14:99132.

32. Edleson JL. The overlap between child maltreatment and woman battering. Violence against Women 1999;5:134-54.

33. De Shazer S. Clues: Investigating solutions in brief therapy. New York, NY, Norton, 1988.

34. Pardoen J, Boeke H. Code oranje (wees alert). Het kwetsbare vertrouwen van ouders in de jeugdgezondheidszorg. Ouders Online, feb 2011.

\section{CORRESPONDENTIEADRES}

Remy M. Vink, TNO Child Health, Postbus 2215, 2301 CE Leiden, tel. 088-8666199 of 06-21134483, e-mail: remy.vink@tno.nl 